\title{
An Optimal Replenishment Policy for the EPQ Model with Permissible Delay in Payments
}

\author{
Shih-Ming Ou*, Kuo-Kuang Chang** \\ * Fuzhou College of Foreign Studies and Trade, China \\ ** University of Kang Ning, China
}

\begin{tabular}{l} 
Article Info \\
\hline Article history: \\
Received Jun 4, 2015 \\
Revised Aug 6, 2016 \\
Accepted Aug 15, 2016 \\
\hline
\end{tabular}

\section{Keyword:}

Delay in payments

EPQ

Optimal replenishment policy

\begin{abstract}
Most of the past researches on economic replenishment quantity did not consider the trade credit period. In practice, however, companies in Taiwan have shown that taking the trade credit period into account when they are making inventory decisions decreases costs substantially. The aim of this paper is to develop an inventory model that incorporates a delay in payments to minimize the total inventory-relevant cost. The optimal replenishment policy of the proposed model is identified by utilizing the global optimum conditions and non-constrained quadratic nonlinear programming. The results show that the existence of global optimal inventory cycle under the condition of total cost function is convex. Accordingly, the proposed model can assist managers in effectively addressing EPQ issue under competitive market.
\end{abstract}

\section{Corresponding Author:}

Shih-Ming Ou,

Fuzhou College of Foreign Studies and Trade,

China.

Email: benao13@gmail.com

\section{INTRODUCTION}

Inventory is one of the most important assessments when a firm attempts to improve the efficiency of the operations in its supply chain. Inventory control, which is linked to most aspects of production organization, can influence a company's business and has a critical role in the activities of operations management. Therefore, a company can take advantage of tracking stock by shortening the lead time for replenishment and estimating inventory cost as long as the company maintains a sturdy inventory management system.

Goyal (1985) argued that IBM's efforts in integrating their national spare part stock network, developing a new inventory system, and modifying their customer service quality have reduced their total inventory cost by more than $\$ 250,000,000$ and continuously saves the company up to $\$ 20,000,000$ in annual expenses. These findings demonstrate the importance of inventory management in a company's business. High-working capital on inventory could result in expenditures such as holding costs and insurance, and the costs of other personnel matters might dramatically rise. Most manufacturers believe that flawlessly managing their inventory can not only reduce inventory cost but also increase their freedom when they use the capital in their companies.

In reviewing the literature on inventory management, researcher like Wilson (1934) extended the original model and applied it to solve inventory problems in the real world. In addition, most Economic Production Quantity (EPQ) models incorporate the following assumptions:

a. Production rate must be greater than demand

b. There must be instantaneous replenishment 
In fact, the order submitted by retailer usually limits the production problems that supplier need to deal with. Therefore, it is necessary to relax the EPQ assumptions to create an inventory model that will find a better solution for the issues that suppliers face.

Most of the traditional EPQ models assume that retailers pay for the goods immediately when the transaction is completed. In reality, few retailers pay for their goods immediately because most of them use trade credit. The use of trade credit violates the EPQ assumptions. Furthermore, to create a win-win situation, both the supplier and the retailer usually set up a reasonable credit transaction deadline by negotiating with each other. By setting a deadline, the supplier will accrue extra interest, and the retailer will not need to initiate loan financing. When delayed payment is provided by suppliers, the retailer also has the advantage of reducing interest yielded by the fund which uses in the payment of backlog.

Based on the reasons we mention above, we construct a theoretical model that incorporates a delay in payments under conditions that does not allow shortages. We then demonstrate some important properties associate with implementing an optimal replenishment policy. After obtaining the model properties, we generate an example. In the last section of the paper, we provide our conclusions as well as suggestions for further research

\section{LITERATURE REVIEW}

Goyal (1985) suggested an EOQ model with a fixed credit deadline for paying for goods as a promotion that could be provided by the supplier. If the retailer sells the product within the limit, he/she will be spared the interest generated by the funds that must be used to pay for the goods. That is a type of chance cost. If the pay date passes, he/she must pay for the products and the interest generated by the funds that have already been paid to the supplier for the rest of the products that are in stock. Many researchers have extended the above model in different ways.

Chung (1989) investigated the interactions between credit transactions and the time value of currency, and he then employed a discounted cash flow (DCF) model to build a total variant cost function for inventory. In his research, an optimal replenishment policy was provided. Chung (1998) revised the model by Goyal (1985) and also found an optimal order quantity. Huang $(2004,2007)$ rewrote the assumptions made by Goyal (1985) and argued that the selling price and the purchase cost for the product might not be equal in real-world scenarios. Huang also considered the rate of replenishment to be finite and developed his research in two phases: one where the supplier allows the retailer to pay for the products before the credit deadline, and another phase where the retailer also provides his/her customers with permission to delay payments for the sake of increasing the amount of product that is sold. Huang (2007) also discussed a possibility in which the supplier offers partial permission for delays in payment when the actual order quantity is less than a certain amount. He minimized the total cost to ensure that the inventory cycle and the order quantity were optimal.

Liao (2007) investigated a non-instantaneous inventory model of deterioration for items that incorporated delays in payment. Tsao and Sheen (2008) found an optimal selling price and maximized the profit for deterioration items while including permission for delays in payment. Chang, Teng and Goyal (2008) reviewed the literature for inventory models published in the last twenty years and classified these models as non-deterioration items, deterioration items, models that allow shortages, order quantity and inflation. They also suggested further research directions for every model they reviewed.

Chung (2009) constructed a solution procedure for non-instantaneous deteriorating items with permissible delay in payment. Ouyang, Teng, Goyal and Yang (2009) extended the work by Goyal (1985) by making a rule that the promotion cannot be offered if the order quantity submitted by the retailer is below a certain threshold. Furthermore, Ouyang and Chang (2013) improved their work by taking the factor of allowing shortage into account. Chung and Huang (2009) extended the work of Goyal (1985) by using dual variables and the year relevant cost to construct an inventory model. They also proved that the year relevant cost function was convex. A year later, Hu and Liu (2010) adopted the finite replenishment rate assumption and relaxed a condition in which purchase price and selling price must not be consistent as part of their effort to build upon the work of Chung and Huang (2009). Furthermore, they found an optimal inventory policy in the environment they had made. Chang (2010) derived an optimal replenishment policy with stock-dependent demand.

Maihami (2012) developed an optimal replenishment policy for non-instantaneous deteriorating items under permissible delay in payments and partial backlogging. In his research, item price is also controlled. Sarkar (2012 a, b) modeled EOQ under trade credit financing with time-dependent deterioration rate and stock dependent demand, respectively. Moussawi-Haidar and Jaber (2013) incorperated cash management into retailer's lot sizing inventory problem under delay in payments to find the optimal solution for more effective operational and financial decision making. Yang and Chang (2013) and Bhunia, Jaggi, 
Sharma and Sharma (2014) developed a two-warehouse inventory model for deteriorating item with allowing delay in payment and partial backlogging. Yang and Chang (2013) also found that both the optimal present value of the profit and the optimal replenishment cycle are sensitive on the selling price and demand.

Meca, Timmer, García-Jurado and Borm (2004) studied a class of inventory games. They developed an EOQ model as the situation which a group of retailers make joint orders for a common item. Li, Feng and Zeng (2014) extended their model by allowing retailer's delay in payments which is offered by the supplier.

\section{THE MODEL}

\subsection{Notations}

$\begin{array}{ll}D & \text { Demand rate } \\ P & \text { Production rate } \\ h & \text { Holding cost per unit of product in stock } \\ I_{\max } & \text { Maximum inventory level } \\ t_{l} & \text { The time point when the quantity of products in stock reaches } I_{\max } \\ T & \text { Inventory cycle } \\ s & \text { Sale price } \\ c & \text { Purchase price } \\ I_{m} & \text { Inventory level at the time point of } t=M \\ I_{e} & \text { Interest income for the unit fund } \\ I_{k} & \text { Interest yielded by the unit fund, which is used to pay for the product in stock. } \\ M & \text { Credit transaction deadline } \\ T V C(T) & \text { Total cost function }\end{array}$

\subsection{Assumptions}

\section{A3.1 Single product with non-deteriorating properties}

A3.2 If both $D$ and $P$ are known and constant, it is reasonable to assume that $P>D$

A3.3 Purchase price and sale price of the product are both constant and $S>c$

A3.4 Instant replenishment

A3.5 $I_{k} \geq I_{c}$

A3.6 When $0 \leq T \leq M$, the retailer does not have to pay for the interest, $I_{e}$, for the products in stock. Otherwise, when $0 \leq M \leq T$, the retailer needs to pay the interest, $I_{k}$.

\subsection{Model Formulation}

Based on the above notation and assumptions, the inventory model is developed and is presented in Figure 1.

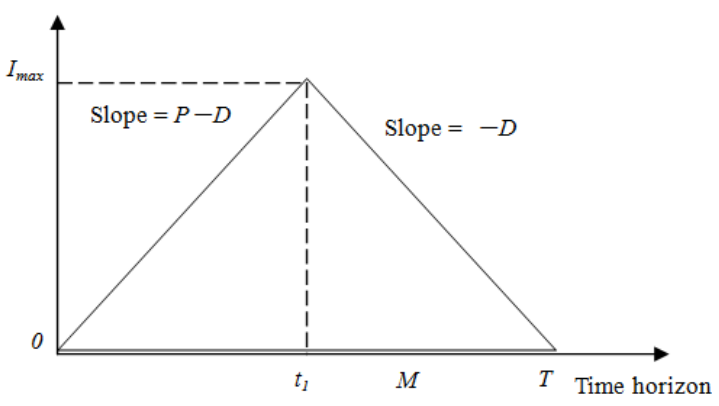

Figure 1. The inventory level during $0 \leq M \leq T$

We then investigate the optimal replenishment policy under the conditions of $0 \leq M \leq T$ and $0 \leq T \leq$ $M$, respectively.

The objective of the model is to minimize the total cost. Thus, we first define the total cost as equal to the sum of the holding cost, the interest yielded by the funds used to pay for the product in stock and the 
negative interest income. By using some triangular properties, we find the formulas of $t_{1}=\frac{D T}{P}$ and $I_{\max }=$ DT $\left(1-\frac{D}{P}\right)$ for computing other cost functions and determining the properties of an optimal policy.

The holding cost is:

$$
h\left[\int_{0}^{T} I(t) d t\right]=\frac{h D T^{2}}{2}\left(1-\frac{D}{P}\right)
$$

Case I: $0 \leq t_{1} \leq M \leq T$

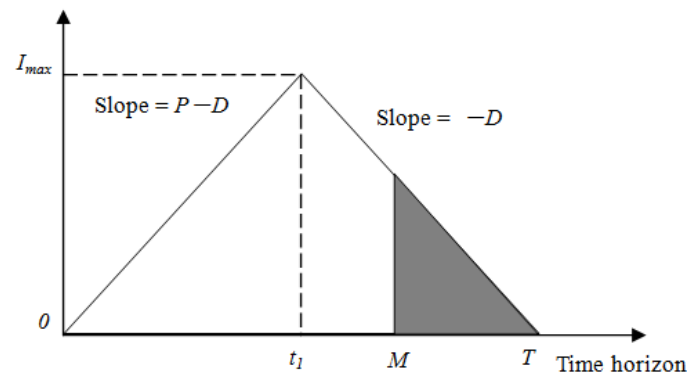

Figure 2. The interest yielded by the unit fund, which is used to pay for the product in stock during $0 \leq M \leq T$

The interest yielded by the unit fund, which is used to pay for the product in stock during inventory cycle $\mathrm{T}$ is:

$c I_{k} \int_{M}^{T} I(t) d t=\frac{c I_{k} D(T-M)^{2}}{2}$

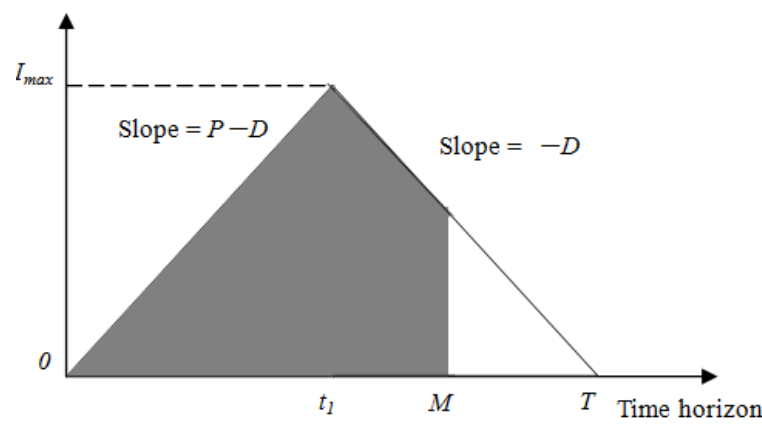

Figure 3. The interest income during $0 \leq M \leq T$

It is reasonable to assume that interest income is the sum of chance cost yielded by the unpaid payments of the products and the interest yielded by the income from selling products, that is

$$
c I_{e} \int_{0}^{M} P d t+s I_{e} \int_{0}^{T} D d t=I_{e}(c P M+s D T)
$$

Case II: $0 \leq T \leq M$ 


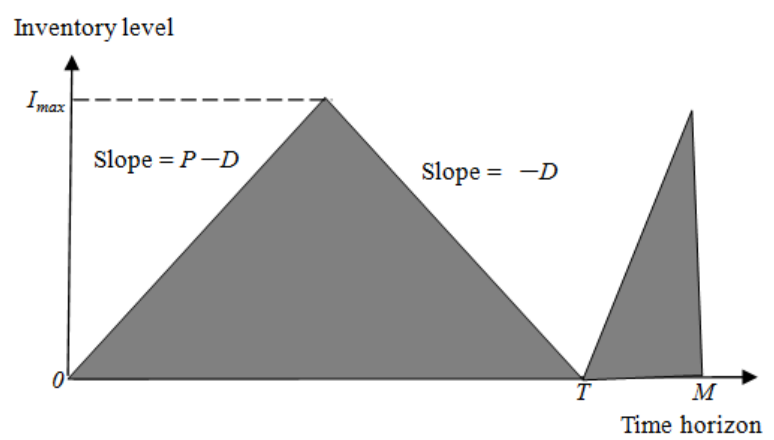

Figure 4. The interest income during $0 \leq T \leq M$

Under this condition, retailers sell all of the products in stock before they have to pay for the products they purchased. Therefore, they do not have to pay interest.

From Figure 4, we construct the function of interest income as follows.

$$
c I_{e} \int_{0}^{t_{1}} P d t+s I_{e} \int_{0}^{T} D d t=I_{e} D T(c+s)
$$

Furthermore, we set up the following total cost, $T V C(T)$, according to the length of credit transaction deadline.

$$
\operatorname{TVC}(T)= \begin{cases}T V C_{1}(T), & 0 \leq \mathrm{t}_{1} \leq M \leq T \\ T V C_{2}(T), & 0 \leq T \leq M\end{cases}
$$

For the two different length of credit limits, the total cost functions can be constructed as follows:

When $0 \leq t_{1} \leq M \leq T$,

$$
T V C_{1}(T)=\frac{h D T^{2}}{2}\left(1-\frac{D}{P}\right)+\frac{c I_{k} D}{2}(T-M)^{2}-I_{e} D T(c+s)
$$

and when $0 \leq T \leq M$,

$$
T V C_{2}(T)=\frac{h D T^{2}}{2}\left(1-\frac{D}{P}\right)-I_{e} D T(c+s)
$$

\subsection{Properties}

We then take the first order derivatives of $T V C_{1}(T)$ and $T V C_{2}(T)$ with respect to inventory cycle, $T$, respectively, and let them equal to 0 . By solving the equation, we obtain the optimal replenishment time.

$$
\begin{aligned}
& \frac{d T V C_{1}(T)}{d T}=h D T\left(1-\frac{D}{P}\right)+c D I_{k}(T-M)-D I_{e}(c+s) \\
& T_{1}^{*}=\frac{\left(c I_{k} M+I_{e}(c+s)\right) P}{h(P-D)+c I_{k} P}
\end{aligned}
$$

To assure that $T_{1}^{*}$ is the global minimum, we take the derivative of (7) with respect to $T$ again.

$$
T_{1}^{*}=\frac{\left(c I_{k} M+I_{e}(c+s)\right) P}{h(P-D)+c I_{k} P}
$$


Lemma 1: When $0 \leq M \leq T$, the sufficient condition under which $T V C_{l}(T)$ is convex is

$$
T>\frac{P I_{e}(c+s)}{h(P-D)}
$$

Proof: The proof is a straightforward consequence of (9) if we set a suitable value, $T^{\prime}$, that makes $T^{\prime}>\frac{P I_{e}(c+s)}{h(P-D)}$ and substitute it into (9).

Denote $T_{1}^{*}$ as the extreme point of $T V C_{1}(T)$, then, we have the following solutions

$$
T V C_{1}^{\prime}(T)\left\{\begin{array}{l}
<0, T \in\left(0, T_{1}^{*}\right) \\
=0, T=T_{1}^{*} \\
>0, T \in\left(T_{1}^{*}, \infty\right)
\end{array}\right.
$$

By repeating the procedure of finding $T_{1}^{*}$, we attempt to find the derivates of $T V C_{2}\left(t_{2}, T\right)$ and $T_{2}^{*}$.

By taking the first order derivative of $T V C_{2}(T)$ with respect to $T$, we obtain

$$
\frac{d T V C_{2}(T)}{d T}=h D T\left(1-\frac{D}{P}\right)+I_{e} D(c+s)
$$

When (11) equals 0 , we obtain the optimal replenishment time after some rearranging.

$$
T_{2}^{*}=\frac{I_{e} P(c+s)}{h(P-D)}
$$
respect to $T$.

Now, to examine the convexity of $T V C_{2}(T)$, we take the second order derivative of $T V C_{2}(T)$ with

$$
\frac{d^{2} T V C_{2}(T)}{d^{2} T}=h D\left(1-\frac{D}{P}\right)
$$

Denote $T_{2}^{*}$ as the extreme point of $T V C_{2}(T)$, then we have the following solutions.

$$
T V C_{2}^{\prime}(T)\left\{\begin{array}{l}
<0, T \in\left(0, T_{2}^{*}\right) \\
=0, T=T_{2}^{*} \\
>0, T \in\left(T_{2}^{*}, \infty\right)
\end{array}\right.
$$

Lemma 2; $T V C_{2}(T)$ is a convex function during $0 \leq M \leq T$. the result.

Proof: From A3.3, it is clearly that (13) is greater than 0 . Therefore, second order condition shows

\section{NUMERICAL EXAMPLE}

To obtain sufficient usage of their production capacity, suppliers will offer retailers a promotion for delaying payments until a credit transaction deadline, $M$. Therefore, the retailers can apply the results found in this paper to build their inventory model. Furthermore, an optimal replenishment policy that dramatically reduces total cost can also be obtained. Data were collected from some companies located in Taiwan and processed with the model. To mimic reality, the parameters used in the proposed model are assigned as follows: 


$$
\begin{array}{llll}
P=50 & D=30 & h=0.1 & c=1 \\
M=1.2 & s=8 & I_{e}=0.01 & I_{k}=0.12
\end{array}
$$

After performing the calculations, we obtain $T_{1}^{*}=1.4625$ and $T_{2}^{*}=1.2$. When $M>t_{2}$, we find that the longer the optimal inventory cycle is, the greater the profit is that retailers could obtain.

As a result, we plot $T V C_{1}$ and $T V C_{2}$ versus $T$ in Figures 5 and 6, respectively. These two figures provide evidence that the aforementioned lemmas are valid. In addition, the delay in payments offered by certain suppliers would result in a negative inventory cost, which also leads to more products being purchased from the suppliers.

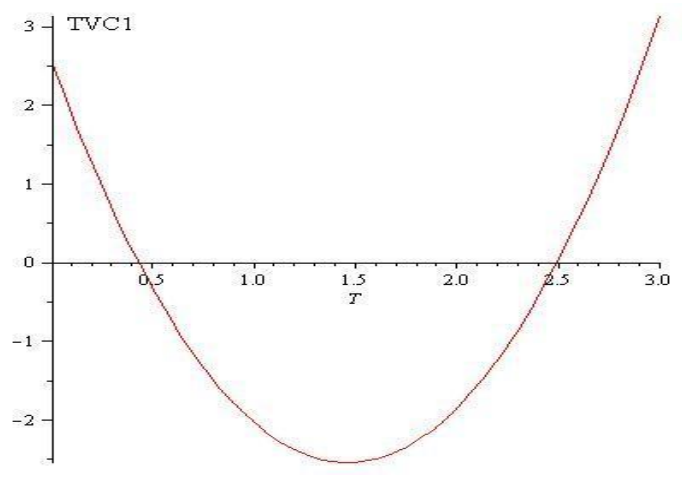

Figure 5. The value of $T V C_{1}$ versus $T$ when $0 \leq t_{1} \leq M \leq T$

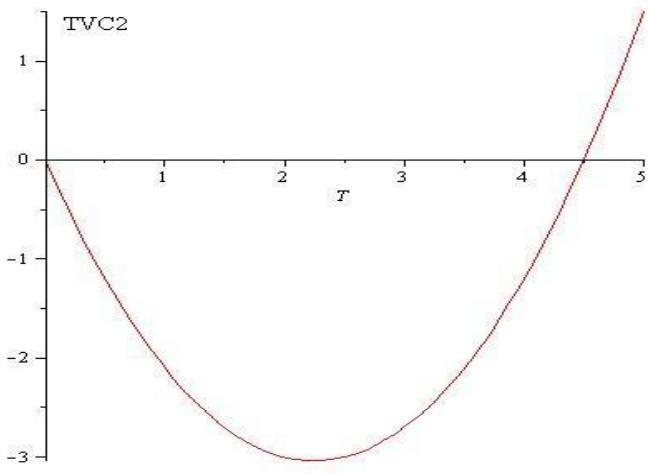

Figure 6. The value of $T V C_{2}$ versus $T$ when $0 \leq T \leq M$

\section{CONCLUSIONS}

The aim of this paper is to develop an inventory model that incorporates delays in payments for impermissible shortages. The proposed model for an optimal replenishment policy is identified by utilizing the global optimal conditions for the Maple-based numerical analysis. The sufficient condition for the existence and uniqueness of the optimal solution has been derived for the system. Theoretical results are developed to find replenishment policies for each system. Our findings show the superiority of the proposed model in contrast with previous studies in a cost-oriented point of view. Moreover, numerical example has been given to illustrate the theoretical results. As shown in Figures 5 and 6, adopting the promotion offered by the suppliers would benefit the retailers' businesses because the retailers would be more willing to purchase products from the suppliers. Therefore, a win-win scenario is achieved. In practice, the proposed model can assist the managers in quantitatively and effectively addressing EPQ issues under competitive circumstance.

Accordingly, in this research, we assume that the product is not deteriorating and that no defective items are produced during the replenishment process. For future analyses, we will relax the assumptions by considering deteriorating items and assuming that the demand rate and replenishment rate follow certain probability distributions (e.g., a Weibull distribution or GAMMA distribution) to provide solutions for replenishment issues in the real world. In addition, taking the factors of inflection and time preference into account would also be worth investigating.

\section{REFERENCES}

[1] Bhunia, A. K., Jaggi, C. K., Sharma, A \& Sharma, R. A Two-warehouse Inventory Model for Deteriorating Items under Permissible Delay in Payment with Partial Backlogging. Applied Mathematics and Computation, 2014, 232, $1125-1137$.

[2] Chang, C. T., Teng, J. T. \& Goyal, S. K. Inventory Lot-size Models under Trade Credits: A Review. Asia-Pacific Journal of Operational Research, 2008, 25, 89-112.

[3] Chang, C. T., Teng, J. T. \& Goyal, S. K. Optimal Replenishment Policies for Non-instantaneous Deteriorating Items with Stock-dependent Demand. International Journal of Production Economics, 2010, 123, 62-68.

[4] Chung, K. H. Inventory Control and Trade Credit Revisited. Journal of Operational Research Society, 1989, 40, 495-498.

An Optimal Replenishment Policy for the EPQ Model with Permissible Delay in Payment ... (Shih-Ming Ou) 
[5] Chung, K. J. A Theorem on the Determination of Economic Order Quantity under Conditions of Permissible Delay in Payments. Computers and Operations Research, 1998, 25, 49-52.

[6] Chung, K. J. \& Huang, C. K. An ordering Policy with Allowable Shortage and Permissible Delay in Payments. Applied Mathematical Modelling, 2009, 33, 2518-2525.

[7] Chung, K. J. A Complete Proof on the Solution Procedure for Non-instantaneous Deteriorating with Permissible Delay in Payment. Computers \& Industrial Engineering, 2009, 56, 267-273.

[8] Goyal, S. K. Economic Order Quantity under Conditions of Permissible Delay in Payments. Journal of Operational Research Society, 1985, 36, 335-338.

[9] Hu, F. \& Liu, D. Optimal Replenishment Policy for the EPQ Model with Permissible Delay in Payments and Allowable Shortages. Applied Mathematical Modelling, 2010, 34, 3108-3117.

[10] Huang, Y. F. Optimal Retailer's Replenishment Policy for the EPQ Model under the Suppliers Trade Credit Policy. Production Planning \& Control, 2004, 15, 27-33.

[11] Huang, Y. F. Optimal Retailer's Replenishment Decisions in the EPQ Model under Two Levels of Trade Credit Policy. European Journal of Operational Research, 2007,176, 1577-1591.

[12] Li, J., Feng, H. \& Zeng, Y. Inventory Games with Permissible Delay in Payments. European Journal of Operational Research, 2014, 234, 694-700.

[13] Liao, J. J. On An EPQ Model for Deteriorating Items under Permissible Delay in Payments. Applied Mathematical Modelling, 2007, 31, 393-403.

[14] Meca, A., Timmer, J., García-Jurado, I. \& Borm,P. Inventory games. European Journal of Operational Research, 2004, 156, 127-139.

[15] Maihami, R. \& Abadi, I. N. K. Joint Control of Inventory and its Pricing for Non-instantaneously Deteriorating items under permissible Delay in Payments and Parial Backlogging. Applied Mathematical Modelling, 2012, 55, $1722-1733$.

[16] Moussawi-Haidar, L. \& Jaber, M. Y. A Joint Model for Cash and Inventory Management for a Retailer under Delay in Payments. Computers \& Industrial Engineering, 2013, 66, 758-767.

[17] Ouyang, L. Y., Teng, J. T., Goyal, S. K. \& Yang, C. T. An Economic Order Quantity Model for Deteriorating Items with Partially Permissible Delay in Payments Linked to Order Quantity. European Journal of Operational Research, 2009, 194, 418-431.

[18] Ouyang, L. Y. \& Chang, C. T. Optimal Production Lot with Imperfect Production Process under Permissible Delay in Payments and Complete Backlogging. International Journal of Production Economics, 2013, 144, 610-617.

[19] Sarkar, B. An EOQ Model with Delay in Payments and Time Varying Deterioration Rate. Mathematical and Computer Modelling, 2012a, 55, 367-377.

[20] Sarkar, B. An EOQ Model with delay in Payments and Stock Dependent Demand in the Presence of Imperfect Production. Applied Mathematics and Computation, 2012b, 218, 8295-8308.

[21] Tsao, Y. C. \& Sheen, G. J. Dynamic Pricing, Promotion and Replenishment Policies for A Deteriorating Item under Permissible Delay in Payments. Computers and Operations Research, 2008, 35, 3562-3580.

[22] Wilson, R. H. A Scientific Routine for Stock Control. Harvard Business Reviews, 1934, 13, 116-118.

[23] Yang, H. L. \& Chang, C. T. A Two-warehouse Partial Backlogging Inventory Model for Deteriorating Items with Permissible Delay in Payment under Inflation. Applied Mathematical Modelling, 2013, 37, 2717-2726. 